\title{
Perfil dos pacientes atendidos em programa comunitário da Liga de Prevenção à Cegueira
}

\author{
Acadêmicas: Juliana Mika Kato, Gabriel de Paula Albuquerque, Carolina Oshiro Yeh, Marina \\ Fonseca Resende, Marcela Feltrin de Barros \\ Orientadores: André Luis Portes, Pedro Carlos Carricondo
}

\begin{abstract}
Introdução: Mutirões são iniciativas essenciais para a identificação de distúrbios visuais em escolares e para o encaminhamento ao serviço especializado quando necessário. O diagnóstico e tratamento precoce garantem melhor prognóstico tanto visual quanto neuropsicossocial da criança e diminuem a evasão escolar. Em parceria com Fundo Social de Solidariedade e secretarias de Estado de Saúde e Educação, o programa comunitário oftalmológico Visão do Futuro garante o atendimento de cerca de 5000 alunos do ensino fundamental da rede pública do Estado de São Paulo anualmente. Os membros da Liga de Prevenção à Cegueira são convidados a participar deste projeto realizando exames de acuidade visual, mobilidade ocular, dilatação, fundoscopia e refração supervisionados por médicos residentes.
\end{abstract}

Objetivo: Divulgar uma das atividades das quais a Liga de Prevenção à Cegueira participa, caracterizando o perfil clínico dos pacientes atendidos em programa comunitário oftalmológico.

Relato da Liga: A Liga atua há 30 anos agregando estudantes de Medicina do $2^{\circ}$ ao $6^{\circ}$ ano interessados em oftalmologia com o intuito de complementar o ensino acadêmico da graduação e aprofundar o aprendizado teórico-prático. As atividades regulares incluem aulas teóricas quinzenais, aulas práticas no ambulatório, wet-lab em olhos de porco, acompanhamentos facultativos no Pronto-Socorro e no Centro Cirúrgico e atendimento nas campanhas Visão do Futuro aos sábados. Há incentivo à participação em projetos de iniciação científica e congressos nacionais, dos quais a Liga tem acesso privilegiado através da Associação Brasileira de Ligas Acadêmicas de Oftalmologia. A Diretoria administrativa é composta por três acadêmicos, quatro médicos residentes e um professor supervisor. Os membros são selecionados anualmente por meio de uma prova teórica.

Metodologia: Estudo retrospectivo de dados coletados em prontuários médicos de pacientes atendidos em campanhas durante $\mathrm{o}$ ano de 2010.

Resultados: Participaram do atendimento 5073 escolares da rede municipal e estadual da cidade de São Paulo nas campanhas realizadas durante o período de estudo. O índice de absenteísmo foi de 54,2\%. Cerca de 1500 óculos foram prescritos e 552 escolares (11\%) foram encaminhados para o ambulatório da instituição. Os diagnósticos mais prevalentes foram estrabismo $(80 \%)$ e ambliopia (19\%). Outros diagnósticos inclúam nistagmo, visão subnormal, alterações no nervo óptico, cicatriz macular, ptose congênita, schivanoma, entre outros.

Discussão e Conclusão: O perfil clínico dos pacientes atendidos em campanhas de prevenção são epidemiologicamente compatíveis com outros estudos na mesma faixa etária. Com o acompanhamento desses pacientes caracteriza-se a demanda gerada por essas campanhas, essencial ao planejamento financeiro do Departamento e à inclusão adequada no serviço. Retifica-se a importância dessa atividade de extensão da Liga de Prevenção à Cegueira não somente no âmbito social como também no aprendizado prático dos membros. 